\title{
О ПРОФЕССИОНАЛЬНОЙ ЭТИКЕ СУДЕБНОГО ЭКСПЕРТА В РОССИЙСКОЙ ФЕДЕРАЦИИ
}

\begin{abstract}
АНнотАцИЯ. Актуальность рассматриваемой темы заключается в том, что в условиях сложной ситуации в судопроизводстве в целом, повышается роль личности судебного эксперта, его соответствия этическим нормам. Поэтому рассмотрены актуальные вопросы разработки основных требований, присущих профессиональной этике судебного эксперта. Рассмотрены критерии соответствия сведущего лица этическим нормам судебного эксперта, формирование его в ходе профессиональной подготовки экспертов. Разработаны рекомендации по повышению уровня ответственности за результаты судебно-экспертного сопровождения процесса формирования доказательственной базы. Показаны сложные ситуации этического характера в деятельности негосударственных судебно-экспертных организаций. Предложены пути выхода из таких ситуаций, в том числе путем создания Общественного совета по судебно-экспертной деятельности в Республике Башкортостан, который призван обеспечить согласование общественно значимых интересов граждан Российской Федерации, научных кругов, судебно-экспертных организаций и органов законодательной, исполнительной, судебной власти субъектов Российской Федерации при реализации ими государственной политики в области судебной экспертизы. Предпринята попытка создания структуры «Кодекса этики судебного эксперта» и формирования содержания некоторых положений данного Кодекса, разработаны рекомендации по совершенствованию законодательства.

кЛючЕВЫЕ словА. Судебная экспертиза; Кодекс этики судебного эксперта; эксперт; суд; судопроизводство; общественный совет; комиссия; негосударственная судебно-экспертная организация.
\end{abstract}

ИНФОРМАЦИЯ О СТАТЬЕ. Дата поступления 22 октября 2016 г.; дата принятия к печати 16 ноября 2016 г.; дата онлайн-размещения 30 ноября 2016 г.

\section{F. G. Aminev \\ Bashkir State University, Ufa, Russian Federation}

\section{ON PROFESSIONAL ETHICS OF THE JUDICIAL EXPERT IN THE RUSSIAN FEDERATION}

\begin{abstract}
The topicality of the considered subject is that in terms of the complicated situation in legal proceedings in general, the role of the identity of the judicial expert, his or her compliance to ethical standards is increasing. Therefore, the article considers topical issues of developing the main requirements inherent in the professional ethics of the judicial expert. It considers the criteria of a competent person's adequacy to the ethical standards of the judicial expert, his or her formation along experts' professional training. It develops recommendations on increasing the level of responsibility for the results of judicial and expert support in the process of drawing up the evidentiary basis. The article presents complicated situations of ethical character in activities of non-governmental judicial and expert organizations. It offers the ways of getting out of these situations, including the one of establishing the Public Council for judicial and expert activities in the Republic of Bashkortostan which is called upon to provide the congruence of publicly significant interests of the citizens of the Russian Federation, the academic community, the judicial and expert organizations and the bodies of legal, executive and judicial power of the Russian Federation entities in their implementing the public policy in the field of forensic
\end{abstract}

\section{Baikal Research Journal}


enquiry. To conclude, an effort is made to create the structure of «Code of Ethics for Judicial Expert» and to draw up the content of certain statements of this Code and to develop recommendations on improving the legislation.

KEYWORDS. Forensic enquiry; Code of Ethics for Judicial Expert; expert; court; legal proceedings; public council; commission; non-governmental judicial and expert organization.

ARTICLE INFO. Received October 22, 2016; accepted November 16, 2016; available online November 30, 2016.

Актуальность изучения проблем судебно-экспертной деятельности, связанных с профессиональной этикой эксперта, объясняется тем, что продолжающаяся оставаться сложной ситуация в досудебном и судебном производстве России, в судопроизводстве в целом, обусловливают повышенное внимание правоохранительных органов, судов, адвокатуры и иных структур к использованию судебной экспертизы, возможности которой постоянно расширяются в связи с интеграцией в сферу судопроизводства новых научно-технических средств и методов [1]. В настоящее время стали обыденными судебно-экспертные исследования в области генотипоскопии и одорологии, палиномии и дендрохронологии, компьютерной техники и полиграфологии. Уделяя повышенное внимание оснащению судебных экспертов инновационным оборудованием и материалами, ни в коем случае нельзя забывать, что субъектом экспертного исследования - лицом, ответственным за результаты профессиональной судебно-экспертной деятельности, является человек - в нашем случае, судебный эксперт. И совершенно правильным следует признать мнение ученых о том, что важен не источник происхождения техники, а ее методическое обеспечение, субъект ее применения в целях расследования преступлений [2]. Поэтому, для реализации обозначенных в ст. 4 Федерального закона «О государственной судебно-экспертной деятельности в Российской Федерации» от 31 мая 2001 г. № 73-ФЗ принципов государственной судебно-экспертной деятельности (законности, соблюдения прав и свобод человека и гражданина, прав юридического лица, а также независимости эксперта, объективности, всесторонности и полноты исследований, проводимых с использованием современных достижений науки и техники), эксперт должен соответствовать требованиям профессиональной этики, честно и добросовестно исполнять свои обязанности, принимать меры к сохранению своих чести и достоинства. У судебного эксперта должны быть ярко выражены такие нравственные начала, как объективность (решение поставленных эксперту задач только на основе независимого объективного научного исследования), принципиальность (исследование и формулирование выводов на основе своих суждений, только в соответствии с научно-обоснованными методиками, без влияния мнений заинтересованных лиц), самокритичность (критическое отношение к ходу и результатам своего экспертного исследования), добросовестность и другие. Таким образом, «экспертная этика складывается из совокупности моральных норм, правил поведения во всех областях профессиональной деятельности" [3]. К моральным нормам, которым должен соответствовать судебный эксперт, следует отнести беспристрастность, самостоятельность, корректность поведения со всеми участниками судопроизводства, коллегами, гражданами. Профессиональная этика эксперта предполагает и творчество, и инициативность в сочетании с постоянной готовностью выполнять свои обязанности.

Экспертная этика должна присутствовать и в процессе взаимодействия экспертов между собой (например, при производстве комиссионных и комплексных экспертиз), с руководителями экспертных организаций и т. д. [4]. При этом, наиболее значимыми моральными нормами судебного эксперта, занимающегося судебно-экспертной деятельностью профессионально, признаются ответственное

\section{Baikal Research Journal}


отношение к своему служебному долгу, к своим профессиональным обязанностям [5]. Также крайне важным условием соблюдения экспертной этики является восприятие судебным экспертом результатов экспертной деятельности как безусловной ценности для общества [6], как важного элемента всего судопроизводства.

До настоящего времени вышеназванные морально-этические качества судебного эксперта не получали документального оформления. Чаще всего предпринимались попытки разработки профессиональной модели эксперта, согласно которой он должен соответствовать основным требованиям профессиограммы судебного эксперта: иметь способность к планированию предстоящих мыслительных действий, высокий уровень интеллектуального развития, гибкость мыслительных процессов, умение выделять из большого количества информации ту, которая необходима для решения данной задачи, способность к анализу и обобщению информации, коммуникативную компетентность (умение слушать, владение вербальными и невербальными средствами общения, самоконтроль), развитые письменно-речевые навыки, умение устанавливать контакты с помощью письменной речи [7]. В таких попытках создания профессиограмм эксперта больше внимания уделялось психологическим, гносеологическим, эмоционально-волевым, коммуникативным аспектам деятельности судебного эксперта, крайне мало упоминалось о моральных качествах.

Представляется, что в условиях продолжающегося реформирования правового регулирования гражданского, уголовного, арбитражного процесса, возникла настоятельная необходимость поддержать предложение Д. А. Сорокотягиной и И. Н. Сорокотягиной по «созданию и принятию кодекса профессиональной этики эксперта, цель которой заключается в установлении основополагающих нравственных норм, определяющих поведение эксперта в конкретной ситуации; формулировании понятия эксперта, четкого обоснования его функций и обязанностей» [8].

Полагаем, что «Кодекса экспертной этики» (или «Кодекса этики судебных экспертов») должен состоять из вводной части и пяти глав. В вводной части должны быть обозначены: определение понятия «судебный эксперт», функции и обязанности судебного эксперта.

Глава 1, названная «Общие положения», должна состоять из статей:

1. Предмет регулирования (дается определение и цели разработанного Кодекса).

2. Сфера применения (пределы распространения действия Кодекса - на всех судебных экспертов, привлекаемых к судопроизводству).

3. Понятия, используемые в Кодексе этики судебных экспертов (специальные знания, судебный эксперт, судебная экспертиза и т. д.).

Глава 2 «Общие требования, предъявляемые к поведению судебного эксперта» должна содержать следующие статьи:

1. Требования о соблюдении законодательства и Кодекса этики судебных экспертов (в данной статье должны быть изложены требования о соблюдении Конституции Российской Федерации, федеральных законов, федерального закона о судебно-экспертной деятельности, других нормативно-правовых актов, регламентирующих судебно-экспертную деятельность).

2. Требования к судебному эксперту, направленные на обеспечение его статуса (в этой статье излагаются следующие основные требования: судебный эксперт должен соответствовать высоким моральным и нравственным критериям, быть честным, добиваясь сохранения личного достоинства, чести, избегая всего, что может нанести ущерб авторитету и репутации судебного эксперта; судебный эксперт должен исключить заключения договоров, подающих повод для формирования финансовых обязательств, с участниками судопроизводства, в которых принимает участие; судебный эксперт не должен совершать действий, позволяющих усомниться в его независимости и беспристрастности и т. д.).

\section{Baikal Research Journal}


Глава 3 «Принципы и правила профессионального поведения судебного эксперта» будет содержать статьи:

1. Принцип независимости (независимость судебного эксперта является основополагающим в судебно-экспертной деятельности: он обязан следовать независимой и беспристрастной позиции в отношении любых участников судопроизводства: и от лиц, назначивших экспертизу, и от сторон и других лиц, заинтересованных в исходе дела; судебный эксперт дает заключение на основе результатов проведенных с использованием специальных знаний исследований в соответствии со своим внутренним убеждением; лица, оказывающие воздействие на судебного эксперта, подлежат ответственности в соответствии с законодательством Российской Федерации).

2. Принцип объективности и беспристрастности (при выполнении своих обязанностей судебный эксперт должен быть свободен от любых предпочтений и предвзятости; его поведение должно быть направлено на исключение всех сомнений в его беспристрастности; судебный эксперт должен заявить самоотвод, если имеются процессуальные основания для отвода или в случае возможности возникновения конфликта интересов; он должен избегать ситуаций, когда личные взаимоотношения с участниками процесса могут вызвать обоснованные подозрения о каких-либо предпочтениях и предвзятом отношении и т. д.).

3. Принцип равенства (судебный эксперт должен придерживаться равного отношения ко всем лицам, участвующим в судопроизводстве; он должен проявлять корректность в общении со всеми участниками процесса, с уважением относиться к нравственным устоям и традициям народов, считаться с культурной самобытностью различных этнических и социальных групп и религий, не допускать конфликтных ситуаций, способных нанести ущерб репутации судебного эксперта; в ходе всех этапов своей деятельности судебный эксперт не показывает свою религиозную принадлежность и т. д.).

4. Компетентность и добросовестность судебного эксперта (судебный эксперт должен постоянно повышать свою квалификацию, совершенствовать свои знания, умения и навыки; он должен знать об изменениях процессуального законодательства, систематически изучать передовой отечественный и зарубежный опыт; не вправе разглашать информацию, полученную при производстве судебной экспертизы; должен быть вежливым, терпеливым в отношении участников судопроизводства и т. д.).

5. Взаимодействие со средствами массовой информации (судебный эксперт должен способствовать профессиональному освещению в средствах массовой информации судебно-экспертной деятельности; предоставлять информацию, способствующую предупреждению правонарушений, выявлению и устранению причин и условий, способствующих их совершению; при освещении судебно-экспертной деятельности в средствах массовой информации нужно проявлять осмотрительность, не комментировать дела, по которым не принято окончательного судебного решения; проявлять сдержанность и осмотрительность, отвечая на публичную критику и т. д.).

Глава 4. «Принципы и правила поведения судебного эксперта во внеэкспертной деятельности» должна содержать следующие статьи:

1. Принципы осуществления внеэкспертной деятельности (судебному эксперту можно заниматься различными видами внеэкспертной деятельности: научной, образовательной, творческой, общественной, благотворительной и иными видами деятельности, не противоречащими законодательству Российской Федерации; ему не рекомендуется заниматься той деятельностью, которая оказывает влияние на независимость и беспристрастность эксперта, приводит к заявлениям об отводе эксперта).

2. Участие в деятельности, связанной с развитием судебной экспертизы (судебный эксперт может участвовать в мероприятиях, направленных на развитие и

\section{Baikal Research Journal}

электронный научный журнал Байкальского государственного университета 
совершенствование судебно-экспертной деятельности и правосудия в целом; вправе выступать с докладами лекциями, участвовать в научных конференциях и семинарах, писать книги и статьи, осуществлять научную и преподавательскую деятельность, в том числе на платной основе и т. д.).

3. Участие в общественной деятельности (судебный эксперт вправе участвовать в общественной деятельности: состоять в качестве члена в профессиональных, благотворительных, образовательных и иных организациях, пребывание в которых не наносит ущерба его профессиональному авторитету).

4. Взаимодействие с органами государственной власти и органами местного самоуправления (судебный эксперт может взаимодействовать с органами законодательной и исполнительной власти, местного самоуправления с целью помощи в решении вопросов права, законодательства, судебно-экспертной деятельности; может участвовать участие в работе комитетов, комиссий, сформированных с участием государственных органов и органов местного самоуправления и т. д.).

5. Вознаграждение, получаемое судебным экспертом в связи с осуществлением внеэкспертной деятельности (судебный эксперт может получать вознаграждение и возмещение расходов за осуществление внеэкспертной деятельности, если источник этих платежей не влечет за собой создание видимости влияния на исполнение судебным экспертом своих профессиональных обязанностей).

6. Участие в профессиональных организациях (судебный эксперт вправе вступать в ассоциации экспертов или другие профессиональные организации для защиты своих интересов и интересов правосудия, совершенствования статуса судебного эксперта, профессиональной подготовки и сохранения своей экспертной независимости; участие в профессиональных судебно-экспертных организациях является добровольным; такие организации должны способствовать защите прав, предоставленных судебным экспертам в соответствии с их статусом и т. д.).

Глава 5. «Заключительные положения» должна содержать одну статью со следующей формулировкой «Вступление в силу Кодекса этики судебных экспертов (указывается, что Кодекс этики судебных экспертов вступает в силу со дня его утверждения общим собранием (съездом) представителей организаций и членов Союза “Палата судебных экспертов имени Ю. Г. Корухова" (или съездом судебных экспертов Российской Федерации)».

Принятие Кодекса этики судебных экспертов на общем собрании (съезде) вышеназванной Палаты объясняется тем, что проведенное анкетирование судебных экспертов негосударственных судебно-экспертных организаций Республики Башкортостан, Республики Татарстан, Челябинской, Свердловской и Пермской областей показало, что 89 \% опрошенных признают некоммерческое партнерство «Палата судебных экспертов» (СУДЭКС) самой авторитетной негосударственной судебно-экспертной организацией.

Полагаем, что скорейшее принятие «Кодекса этики судебного эксперта» будет способствовать повышению уровня судебно-экспертной деятельности и судопроизводства в Российской Федерации в целом.

\section{Список использованной литературы}

1. Аминев Ф. Г. О некоторых проблемах судебно-экспертной деятельности в Российской Федерации / Ф. Г. Аминев // Правовое государство: теория и практика. - 2015. № 4 (42). - C. 127.

2. Головин А. Ю. Криминалистические методы преодоления противодействия расследованию транспортных преступлений : монография / А. Ю. Головин, О. П. Грибунов, А. А. Бибиков. - Иркутск : Вост.-Сиб. ин-т МВД России, 2015. - 164 с.

3. Майлис Н. П. Теория и практика судебной экспертизы в доказывании. Спецкурс : учеб. пособие / Н. П. Майлис. - М. : Юнити-Дана, 2015, 2015. - 263 с.

\section{Baikal Research Journal}

электронный научный журнал Байкальского государственного университета 
4. Аверьянова Т. В. Судебная экспертиза. Курс общей теории / Т. В. Аверьянова. M. : Норма, 2006. - 480 c.

5. Россинская Е. Р. Теория судебной экспертизы (Судебная экспертология) : учебник / Е. Р. Россинская, Е. И. Галяшина, А. М. Зинин. - 2-е изд., перераб. и доп. - М. : Норма, 2016. -368 c.

6. Комиссарова Я. В. Концептуальные основы профессиональной деятельности эксперта в уголовном судопроизводстве : монографии / Я. В. Комиссарова. - М. : Юрлитинформ, 2010. -240 c.

7. Кискина Е. Е. Содержание и структура профессиограммы судебного эксперта / Е. Е. Кискина // Вестник криминалистики. - 2008. - № 3. - С. 77-83.

8. Сорокотягин И. Н. Судебная экспертиза : учеб. и практикум для акад. бакалавриата / И. Н. Сорокотягин, Д. А. Сорокотягина. - М. : Юрайт, 2015. - 288 с. - (Бакалавр. Академический курс).

\section{References}

1. Aminev F. G. On Some Problems of Forensic Activity in the Russian Federation. Pravovoe gosudarstvo: teoriya i praktika = Legal State: Theory and Practice, 2015, no. 4 (42), pp. 126-131. (In Russian).

2. Golovin A. Yu., Gribunov O. P., Bibikov A. A. Kriminalisticheskie metody preodoleniya protivodeistviya rassledovaniyu transportnykh prestuplenii [Criminalistics methods of overcoming counteractions to investigating transport crimes]. Irkutsk, East Siberia Institute of the Russian Internal Affairs Ministry Publ., 2015. 164 p.

3. Mailis N. P. Teoriya i praktika sudebnoi ekspertizy v dokazyvanii. Spetskurs [Theory and practice of forensic inquiry in evidence. A special course]. Moscow, Yuniti-Dana Publ., 2015, 2015. $263 \mathrm{p}$.

4. Averyanova T. V. Sudebnaya ekspertiza. Kurs obshchei teorii [Forensic Inquiry. A Course of General Theory]. Moscow, Norma Publ., 2006. 480 p.

5. Rossinskaya E. R., Galyashina E. I., Zinin A. M. Teoriya sudebnoi ekspertizy (Sudebnaya ekspertologiya) [Theory of Forensic Inquiry (Judicial Expertology)]. 2 ${ }^{\text {nd }}$ ed. Moscow, Norma Publ., 2016. 368 p.

6. Komissarova Ya. V. Kontseptual'nye osnovy professional'noi deyatel'nosti eksperta $v$ ugolovnom sudoproizvodstve [Conceptual basis of the expert's professional activity in criminal procedure]. Moscow, Yurlitinform Publ., 2010. 240 p.

7. Kiskina E. E. Content and structure of the judicial expert's pofessiogram. Vestnik kriminalistiki $=$ Bulletin of Criminalistics, 2008, no. 3, pp. 77-83. (In Russian).

8. Sorokotyagin I. N., Sorokotyagina D. A. Sudebnaya ekspertiza [Forensic Inquiry]. Moscow, Yurait Publ., 2015. 288 p.

\section{Информация об авторе}

Алинев Фарит Гизарович - кандидат юридических наук, доцент, кафедра криминалистики Института права, Башкирский государственный университет, Член Президиума НП «Палата судебных экспертов», исполнительный директор ООО «Урало-Поволжское объединение судебных экспертов», 450076, Республика Башкортостан, г. Уфа, ул. Заки Валиди, 32, e-mail: faminev@mail.ru.

\section{Author}

Farid G. Aminev - PhD in Law, Associate Professor, Chair of Criminalistics, Institute of Law, Bashkir State University, 32 Zaki Validi St., 450076, Ufa, Russian Federation; e-mail: faminev@mail.ru.

\section{Библиографическое описание статьи}

Аминев Ф. Г. О профессиональной этике судебного эксперта в Российской Федерации / Ф. Г. Аминев // Baikal Research Journal. — 2016. - T. 7, № 6. — DOI: 10.17150/2411$\underline{6262.2016 .7(6) .19}$.

\section{Reference to article}

Aminev F. G. On professional ethics of the judicial expert in the Russian Federation. Baikal Research Journal, 2016, vol. 7, no. 6. DOI: 10.17150/2411-6262.2016.7(6).19. (In Russian).

\section{Baikal Research Journal}

